BMJ Open

Diabetes

Research

\& Care

\title{
Multiple complications among people with diabetes from Finland: an 18-year follow-up in 1994-2011
}

\author{
Erja Forssas, ${ }^{1}$ Martti Arffman, ${ }^{1}$ Kristiina Manderbacka, ${ }^{1}$ Ilmo Keskimäki, ${ }^{1,2}$ \\ liris Ruuth, ${ }^{1}$ Reijo Sund ${ }^{3}$
}

To cite: Forssas $\mathrm{E}$, Arffman M, Manderbacka K, et al. Multiple complications among people with diabetes from Finland: an 18-year follow-up in 1994-2011. BMJ Open Diabetes Research and Care 2016;4:e00254. doi:10.1136/bmjdrc-2016000254

Preliminary results of the study have been presented in poster form in European Public Health Congress in Glasgow, Scotland, 19-22 November 2014

Received 21 April 2016 Revised 25 August 2016 Accepted 16 September 2016

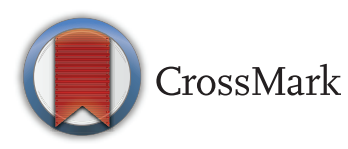

\footnotetext{
${ }^{1}$ Service System Research Unit, National Institute for Health and Welfare, Helsinki, Finland

${ }^{2}$ School of Health Sciences, University of Tampere, Tampere, Finland ${ }^{3}$ Centre for Research Methods, University of Helsinki, Helsinki, Finland
}

Correspondence to Martti Arffman; martti.arffman@thl.fi

\section{ABSTRACT}

Objective: In this study, we examined trends in severe diabetes-related complications (acute myocardial infarction, stroke, lower extremity amputation, and endstage renal disease) and prevalence of multiple complications in a total population with diabetes in Finland during an 18-year period.

Research design and methods: The total population with diabetes aged 30 years or older in 1994-2011 was obtained from several Finnish health registers. Only the first episode of each end point was included in the analysis. We examined trends in the prevalence of these end points using agestandardization and changes in these end points were analyzed using repeated-measures Poisson regression models.

Results: The prevalence of single comorbidities decreased during the study period, especially for acute myocardial infarction and stroke. The age-adjusted and diabetes duration-adjusted risk of having one of these end points decreased throughout the study period among persons with type 2 diabetes. Among women, the risk ratio was 0.71 (0.63 to 0.79 ) in 2006-2011 compared to 1994-1999, and among men, the figure was 0.72 (0.66 to 0.78 ). In type 1 diabetes, the risk of multiple serious complications increased. We further found increased mortality risk among persons with any of these complications irrespective of diabetes type.

Conclusions: Our results concerning the development of risk of complications suggest improvements in the management of diabetes. More attention needs to be paid to the prevention of complications among older persons and those with longer history of diabetes to prevent clustering of complications and to prevent the diabetes epidemic in the population to reduce the public health burden of diabetes.

\section{INTRODUCTION}

Population with diabetes is growing worldwide due to an epidemic of type 2 diabetes ${ }^{12}$ and an increase in the incidence of type 1 diabetes. ${ }^{2}{ }^{3}$ Further, improvements in the diagnostic methods and earlier detection of diabetes as well as improvements in diabetes care increasing the life expectancy of patients with diabetes have had an effect.

\section{Significance of this study}

What is already known about this subject?

- There is a growing literature concerning multimorbidity in general including also diabetes and concerning single complications of diabetes. The studies show that the main burden to population health and healthcare comes from its microvascular and macrovascular complications.

\section{What are the new findings?}

- Our results show a marked decrease in risk of one serious complication during the study period among persons with type 2 diabetes, mainly driven by decrease of acute myocardial infarction and stroke among persons with diabetes.

- However, according to our results, the risk of multiple complications did not decrease among persons with type 1 diabetes. This is likely to be associated with aging of the diabetes population and with advances in care increasing the likelihood of survival with complications.

How might these results change the focus of research or clinical practice?

- An important question for future studies is whether there have been actual improvements in the prevention of complications among persons with already existing diabetes.

- More attention needs to be paid to the prevention of complications among older persons and those with longer history of diabetes to prevent clustering of multiple complications and to prevention of diabetes epidemic in the population to reduce the public health burden of diabetes.

Diabetes requires continuous medical attention, including multifactorial risk reduction, supporting patient self-management, prevention of acute complications, and reduction of the risk of long-term complications. ${ }^{4}$ The main burden to population health and healthcare comes from its microvascular and macrovascular complications. ${ }^{5}$

While there is a growing literature concerning multimorbidity in general including 
also diabetes, ${ }^{6-8}$ and concerning single complications of diabetes, ${ }^{9-14}$ studies investigating how several complications of diabetes cluster among individuals have mainly examined complications as part of a broader framework of multimorbidity and have mainly been based on regional samples. ${ }^{15} 16$

The aim of this study was to examine trends in acute myocardial infarction (AMI), stroke, lower extremity amputation, and end-stage renal disease (ESRD) representing important complications of diabetes among people aged 30 years or older in a total population with diabetes in Finland between 1994 and 2011.

\section{RESEARCH DESIGN AND METHODS \\ Population with diabetes}

The population with diabetes was defined as those having any diabetes-related entries in any of the following registers: the Hospital Discharge Register, the Cause of Death Register, the Finnish Kidney Register, and drug registers of the Social Insurance Institution between 1964 and 2011 and alive in 1 January 1994. For these persons, information regarding the use of hospital services and causes of death was individually linked using the personal identification code unique to each individual. Diabetes type was determined by register entries concerning drug use: persons having entries on continuous use of insulin but no signs of drug use increasing insulin production of the pancreas were defined as having type 1 diabetes. Population at risk was defined as persons with diabetes aged 30 years or older in 19942011. We formed annual cohorts of all individuals with diabetes and alive in the beginning of the year and those with incident diabetes during that year. Since we examined complications of diabetes, the diabetes diagnosis needed to precede the complication entry. Persons with gestational diabetes only were excluded from the analyses.

Diabetes-related complications were defined as right for elevated health insurance reimbursement for drug costs due to each of these complications granted by the Social Insurance Institution, or an entry in the Hospital Discharge Register, or Cause of Death Register or the Finnish Kidney Register. We examined the following complications: (1) stroke (ICD-9 and ICD-10 codes: 430*, 431*, 4330A, 4331A, 4339A, 4340A, 4341A, 4349A, I60*, I61*, I63*), (2) AMI (ICD-9 and ICD-10 codes: $410 *, \mathrm{I} 21 *-\mathrm{I} 22 *)$, (3) lower extremity amputation (LEA) (Finnish Hospital League codes: 9571-9575, NOMESCO codes: NFQ10, NFQ20, NGQ10, NGQ20, NHQ10, NHQ20, NHQ30, or NHQ40), and (4) ESRD (entry in the Finnish Kidney Register concerning the onset of renal replacement therapy or cause of death codes 5855 , 5856, N185, or N186). We examined the first register entry of each complication only as they are chronic conditions. By only counting the first register entry, we wanted to ensure not counting the same complication several times as each of the complications can result to entries in different registers and several entries in the hospital discharge register.

\section{Statistical analyses}

We examined trends in the prevalence of these complications by calculating age-standardized rates per 1000 using the 2011 diabetes population as a standard. Multivariate analyses were based on repeated-measures Poisson regression models controlling for age and diabetes duration. Separate models were calculated for men and women. Trends in the clustering of complications were analyzed by comparing prevalence in 19941999 to two later periods (2000-2005 and 2006-2011). We further examined interactions between age and period as well as duration of diabetes and period to study whether the development was similar in different subgroups. In additional analyses, we conducted Cox regression models using counting process data to study the effect of the four complications on survival until death or censoring at the end of year 2011. Models were fitted for people with type 1 and type 2 diabetes separately and adjusted for gender, age, study period, and duration of diabetes. Ethical approval for the study was received from the Research Ethics Committee of the National Institute for Health and Welfare.

\section{RESULTS}

There were altogether 145738 persons with diabetes in 1994. The population with diabetes increased rapidly during the study period (table 1) as did the proportion of men in the population. More than $80 \%$ of the population had type 2 diabetes in 1994 and the proportion increased to $90 \%$ during the study period. The mean duration of diabetes was longer toward the end of the

Table 1 Basic background characteristics of the population with diabetes in 1994 and 2011 in Finland

\begin{tabular}{lll}
\hline Year & $\mathbf{1 9 9 4}$ & $\mathbf{2 0 1 1}$ \\
\hline $\mathrm{n}$ & 145738 & 342028 \\
& $\%$ & $\%$ \\
Gender & & \\
Male & 44 & 51 \\
Female & 56 & 49 \\
Diabetes type & & \\
Type 1 & 17 & 10 \\
Type 2 & 83 & 90 \\
Age (years) & & \\
30-44 & 10 & 7 \\
45-64 & 31 & 35 \\
65-74 & 28 & 28 \\
$75-84$ & 23 & 21 \\
$85+$ & 9 & 9 \\
Diabetes duration (mean (SD)) & \\
Type 1 & $15.7(9.0)$ & $20.3(14.4)$ \\
Type 2 & $6.3(6.7)$ & $7.3(7.2)$ \\
\hline
\end{tabular}



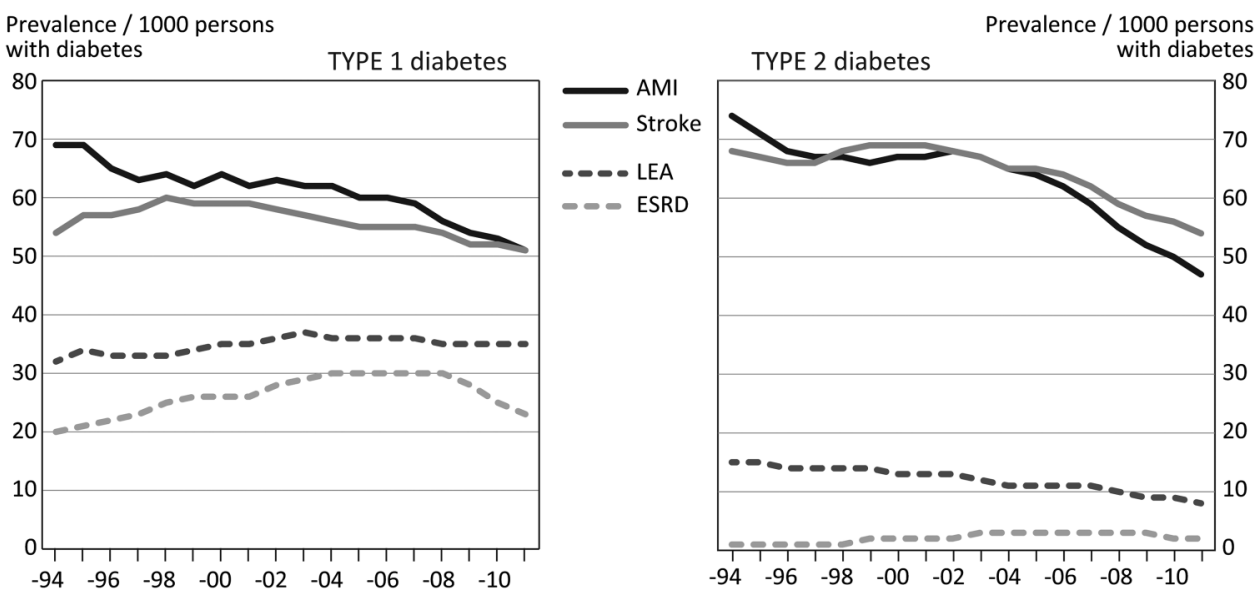

Figure 1 The prevalence of complications (per 1000) among persons with diabetes in 1994-2011 in Finland by diabetes type. AMI, acute myocardial infarction; ESRD, end-stage renal disease; LEA, lower extremity amputation.

study period among type 1 and type 2 diabetes population.

Figure 1 presents age-standardized trends in each complication examined from 1994 to 2011 by diabetes type. AMI and stroke were common among both patient groups. Whereas AMI rates decreased during the study period by a third among patients with type 2 diabetes and by a fourth among patients with type 1 diabetes, the decline in stroke was $21 \%$ among persons with type 2 diabetes and only $5 \%$ among those with type 1 diabetes. LEA rates were much higher among persons with type 1 diabetes and remained on the same level throughout the study period, but decreased by almost $50 \%$ among those with type 2 diabetes. ESRD rates were much higher among persons with type 1 diabetes and remained similar throughout the study period among both patient groups.

Since the prevalence of most complications studied decreased in time, we examined the risk of co-occurrence of one and of several complications with diabetes adjusted for age and duration of diabetes, in three time periods comparing years 2000-2005 and
2006-2011 to the beginning of the study period (19941999) by diabetes type (table 2). The risk of having one complication remained on approximately the same level for persons with type 1 diabetes among men and women throughout the study period. Among persons with type 2 diabetes, the risk of having one complication decreased steadily during the study period among both genders. The risk of having two or more complications increased by $>25 \%$ from 1994-1999 to the beginning of the 2000s among men and women with type 1 diabetes and remained on the same level after that. Among persons with type 2 diabetes, the risk of having two or more complications diminished especially toward the end of the study period.

We then examined whether the development in time was similar among different age groups and by diabetes duration. No significant interactions were found among either men or women with type 1 diabetes. However, the risk of having one complication among persons with type 2 diabetes and the risk of having two complications among men were significantly more pronounced among older persons (all $\mathrm{p}$ values $<0.05$ ) and those with longer

Table 2 Change in age-standardized risk of multiple complications among persons with diabetes aged 30 years or older in 2000-2005 and 2006-2011 compared to period 1994-1999 (1.00), risk ratios, and their 95\% Cls controlling for diabetes duration

\begin{tabular}{|c|c|c|c|c|}
\hline & \multicolumn{2}{|l|}{ Type 1} & \multicolumn{2}{|l|}{ Type 2} \\
\hline & $2000-2005$ & 2006-2011 & $2000-2005$ & 2006-2011 \\
\hline \multicolumn{5}{|l|}{ Women } \\
\hline 1 complication & $1.06(1.01 \text { to } 1.12)^{\star}$ & 1.00 (0.94 to 1.07$)$ & $0.89(0.80 \text { to } 0.98)^{\star}$ & $0.71(0.63 \text { to } 0.79)^{\star \star *}$ \\
\hline$\geq 2$ complications & $1.31(1.14 \text { to } 1.50)^{\star \star \star}$ & $1.27(1.09 \text { to } 1.47)^{\star \star}$ & 0.96 (0.80 to 1.16$)$ & $0.72(0.59 \text { to } 0.89)^{\star \star \star}$ \\
\hline \multicolumn{5}{|l|}{ Men } \\
\hline 1 complication & 1.00 (0.95 to 1.05$)$ & $0.95(0.90 \text { to } 1.00)^{*}$ & $0.89(0.83 \text { to } 0.96)^{\star \star}$ & $0.72(0.66 \text { to } 0.78)^{\star \star \star}$ \\
\hline$\geq 2$ complications & $1.26(1.10 \text { to } 1.43)^{\star \star \star}$ & $1.23(1.08 \text { to } 1.40)^{\star \star}$ & 1.09 (0.95 to 1.26$)$ & $0.84(0.72 \text { to } 0.97)^{\star}$ \\
\hline
\end{tabular}


duration of diabetes (all p values $<0.01$ ) toward the end of the study period.

We further analyzed excess mortality risk associated with these complications. Significantly increased mortality risk was found for each of the complications studied among persons with type 1 and type 2 diabetes (table 3 ). The mortality risk was highest and more than threefold among persons with AMI or ESRD irrespective of diabetes type.

\section{CONCLUSIONS}

\section{Overview of main results}

This register-based study followed persons aged 30 years and older with diabetes through an 18-year period and examined the prevalence of four complications of diabetes. While AMI and stroke rates were on similar level regardless of diabetes type, LEA and ESRD were much more common among persons with type 1 diabetes. Additionally, complication rates decreased less among persons with type 1 diabetes during the study period. The decrease in LEA rates among persons with type 2 diabetes is in line with earlier results suggesting decreasing amputation rates among persons with diabetes in Finland ${ }^{13}$ and elsewhere. ${ }^{11}$ Additionally, AMI and stroke rates decreased in both patient groups in line with earlier results. ${ }^{9} 15$ The risk of one serious complication decreased during the study period among persons with type 2 diabetes suggesting advances in secondary prevention. However, part of the decrease especially among persons with type 2 diabetes is likely to be due to improvements in early diagnosis of the disease increasing the number of persons with a milder stage of disease in the population. The risk of multiple complications did not decrease among persons with type 1 diabetes, which is likely to be due to aging of the diabetes population and advances in medical care increasing the likelihood of survival with complications. Nevertheless, we still found increased mortality risk among persons with

Table 3 Mortality risk among persons with diabetes in 1994-2011 by diabetes type (HRs and their 95\% Cls controlling for gender, age, period, diabetes duration, and all studied complications)

\begin{tabular}{|c|c|c|c|c|}
\hline \multirow[b]{2}{*}{ Complication } & \multicolumn{2}{|l|}{ Type 1} & \multicolumn{2}{|l|}{ Type 2} \\
\hline & HR & $95 \% \mathrm{Cl}$ & HR & $95 \% \mathrm{Cl}$ \\
\hline Stroke & $2.23^{\star \star *}$ & $\begin{array}{l}2.13 \text { to } \\
2.34\end{array}$ & $2.25^{\star \star \star}$ & $\begin{array}{l}2.22 \text { to } \\
2.28\end{array}$ \\
\hline AMI & $3.88^{\star * *}$ & $\begin{array}{l}3.72 \text { to } \\
4.04\end{array}$ & $3.35^{\star \star \star}$ & $\begin{array}{l}3.31 \text { to } \\
3.40\end{array}$ \\
\hline LEA & $2.17^{\star \star \star *}$ & $\begin{array}{l}2.05 \text { to } \\
2.29\end{array}$ & $2.11^{\star \star \star}$ & $\begin{array}{l}2.06 \text { to } \\
2.17\end{array}$ \\
\hline ESRD & $3.13^{\star \star *}$ & $\begin{array}{l}2.90 \text { to } \\
3.39\end{array}$ & $3.05^{\star \star \star}$ & $\begin{array}{l}2.84 \text { to } \\
3.28\end{array}$ \\
\hline
\end{tabular}

${ }^{\star * *} \mathrm{p}<0.001$.

AMI, acute myocardial infarction; ESRD, end-stage renal disease;

LEA, lower extremity amputation. any of these complications. The mortality risk was highest among persons with AMI and ESRD.

\section{Methodological considerations}

Our research data and indicators of complications were based on several large administrative registers the validity of which has, in general, been estimated to be good. ${ }^{17} 18$ As AMI, stroke, LEA, and ESRD are serious conditions not treated in ambulatory care, most cases are likely to be captured by the registers used in the current study. A limitation of our study is that we could not examine retinopathy, since comprehensive register data concerning it do not exist in Finland. Our data on drug use were based on reimbursement data of actual drug costs and entitlements for elevated reimbursement of drug costs based on standardized diagnostic criteria; false-positive cases are therefore likely to be rare. Our results cover complications among persons with diabetes diagnosed in the healthcare system and treated with drugs, as those with diabetes treated with diet only could not be identified from the registers. Our data set has, however, been shown to have relatively good coverage in comparison to a local diabetes register from the Metropolitan area. ${ }^{19}$ Definition of diabetes type using register data only is a challenge, and our definition was based on actual drug purchases among persons with diabetes. We could not examine the potential improvements made in ambulatory care in the prevention of complications suggested by our results, since Finnish registers do not currently cover comparable data concerning ambulatory service use or clinical content of care for the whole country.

\section{Conclusions}

Our results suggest improvements in the management of diabetes, but there are still patient groups among whom more attention needs to be paid to multifactorial management of risk factors (glucose level, blood pressure, lipid level, smoking) in order to avoid serious complications and clustering of multiple complications. ${ }^{20}$ More attention needs to be paid to the prevention of complications among older persons and those with longer history of diabetes to prevent clustering of multiple complications and to prevention of diabetes epidemic in the population to reduce the public health burden of diabetes.

Acknowledgements The authors would like to thank the Finnish Diabetes Association and the Social Insurance Institution for collaboration in the forming of the data set.

Contributors EF contributed to the conception and design of the study, planning and executing of analyses, and drafted the manuscript. MA contributed to the conception and design of the study, the statistical analyses, and took part in the revision of the manuscript for important intellectual content. KM contributed to the conception of the study and interpretation of the results and took part in the revision of the manuscript for important intellectual content. IR contributed to the conception and design of the study, forming the data, and took part in the revision of the study. IK and RS contributed to the conception and design of the study, planning of analyses, and took part in the revision of the manuscript for important intellectual content. RS acts as a guarantor of the paper. All authors have read and approved the final manuscript. 
Funding This work was supported by the Academy of Finland (projects number 277939 and 254 121).

Disclaimer The Academy of Finland had no involvement in its design, data collection, findings, or decision to publish.

Competing interests None declared.

Ethics approval The Research Ethics Committee of THL.

Provenance and peer review Not commissioned; externally peer reviewed.

Data sharing statement According to the Finnish data protection legislation, data including sensitive health information can only be used by named individuals who have signed the pledge of secrecy for specifically defined research purposes. Therefore, no additional data are available for data sharing purposes.

Open Access This is an Open Access article distributed in accordance with the Creative Commons Attribution Non Commercial (CC BY-NC 4.0) license, which permits others to distribute, remix, adapt, build upon this work noncommercially, and license their derivative works on different terms, provided the original work is properly cited and the use is non-commercial. See: http:// creativecommons.org/licenses/by-nc/4.0/

\section{REFERENCES}

1. Passa P. Diabetes trends in Europe. Diabetes Metab Res Rev 2002;18:S3-8.

2. Lammi N, Blomstedt PA, Moltchanova E, et al. Marked temporal increase in the incidence of type 1 and type 2 diabetes among young adults in Finland. Diabetologia 2008;51:897-9.

3. Harjutsalo V, Sjoberg L, Tuomilehto J. Time trends in the incidence of type 1 diabetes in Finnish children: a cohort study. Lancet 2008;371:1777-82.

4. American Diabetes Association. Standards of medical care in diabetes 2015. Diabetes Care 2015;38(Suppl 1):S1-96.

5. Clarke PM, Glasziou P, Patel A, et al. Event rates, hospital utilization, and costs associated with major complications of diabetes: a multicountry comparative analysis. PLOS Med 2010;7: e1000236.
6. Kirchberger I, Meisinger $\mathrm{C}$, Goluke $\mathrm{H}$, et al. Long-term survival among older patients with myocardial infarction differs by educational level: results from the MONICA/KORA myocardial infarction registry. Int J Equity Health 2014:13:19.

7. Boutayeb A, Boutayeb S, Boutayeb W. Multi-morbidity of non-communicable diseases and equity in WHO Eastern Mediterranean countries. Int J Equity Health 2013:12:60.

8. Pefoyo AJ, Bronskill SE, Gruneir A, et al. The increasing burden and complexity of multimorbidity. BMC Public Health 2015;15:415.

9. Fox CS, Coady S, Sorlie PD, et al. Trends in cardiovascular complications of diabetes. JAMA 2004;292:2495-9.

10. Ward MM. Access to care and the incidence of end-stage renal disease due to diabetes. Diabetes Care 2009;32:1032-6.

11. Schofield CJ, Yu N, Jain AS, et al. Decreasing amputation rates in patients with diabetes-a population-based study. Diabet Med 2009;26:773-7.

12. Booth GL, Hux JE, Fang J, et al. Time trends and geographic disparities in acute complications of diabetes in Ontario, Canada. Diabetes Care 2005;28:1045-50.

13. Ikonen TS, Sund R, Venermo M, et al. Fewer major amputations among individuals with diabetes in Finland in 1997-2007: a population-based study. Diabetes Care 2010;33:2598-603.

14. van Houtum WH, Rauwerda JA, Ruwaard D, et al. Reduction in diabetes-related lower-extremity amputations in The Netherlands: 1991-2000. Diabetes Care 2004;27:1042-6.

15. Alonso-Moran E, Orueta JF, Fraile Esteban Jl, et al. The prevalence of diabetes-related complications and multimorbidity in the population with type 2 diabetes mellitus in the Basque Country. BMC Public Health 2014;14:1059.

16. Wandell PE, Gafvels C. Patients with type 2 diabetes aged 35-64 years at four primary health care centres in Stockholm County, Sweden. Prevalence and complications in relation to gender and socio-economic status. Diabetes Res Clin Pract 2004;63:195-203.

17. Gissler M, Haukka J. Finnish health and social welfare registers in epidemiological research. Norsk Epidemiologi 2004;14:113-20.

18. Sund R. Quality of the Finnish Hospital Discharge Register: a systematic review. Scan J Public Health 2012;40:505-15.

19. Sund R, Harno K, Ranta S, et al. Evaluation of case inclusion in two population-based diabetes registers. Finn $\mathrm{J}$ eHealth eWelfare 2010;2:136-46. http://ojs.tsv.fi/index.php/stty/article/view/3620

20. Gaede $\mathrm{P}$, Lund-Andersen $\mathrm{H}$, Parving $\mathrm{HH}$, et al. Effect of a multifactorial intervention on mortality in type 2 diabetes. $N$ Engl J Med 2008;358:580-91. 